\title{
Sequential Surgical Treatment for Congenital Monocular Elevation Deficiency and Exotropia: A Case Report
}

\author{
V. Chandrasekhara Reddy, and S. Chandrasekhara Reddy
}

\section{ABSTRACT}

\begin{abstract}
A 20-year-old lady presented with drooping of left upper eyelid since childhood. After detailed examination she was diagnosed to have congenital monocular elevation deficiency and exotropia in the left eye. Sequential surgical correction procedures were performed to treat her left eye condition i.e., first surgery to correct exotropia (recession and resection of the horizontal recti), second surgery to correct hypotropia (recession and resection of vertical recti) without Knapp's or modified Knapp's proceadure. Left eye was looking straight in primary position; however, there was hypertropia in the right eye. Third surgery was done to correct hypertropia in the right eye (recession and resection of vertical recti) following which both eyes were straight in primary position. Even though the patient has undergone surgery three times, she was very happy with good cosmetic results.
\end{abstract}

Keywords: Exotropia, hypotropia, monocular elevation deficiency, resection, recession.
Submitted : August 9, 2021

Published : August 31, 2021

ISSN: 2593-8339

DOI: $10.24018 /$ ejmed.2021.3.4.1009

\section{C. Reddy}

Department of Pediatric Ophthalmology, Osmania Medical College \& Sarojini Devi Eye Hospital/Regional institute of Ophthalmology/Government eye hospital, Hyderabad, Telangana, India. S. C. Reddy

Department of Ophthalmology, Faculty of Medicine and Defence Health, National Defence University of Malaysia, Kuala Lumpur, Malaysia. (e-mail: profscreddy@gmail.com)

*Corresponding Author

\section{INTRODUCTION}

Monocular elevation deficiency (MED) is defined as limitation of elevation of the affected eye in primary gauze as well as adduction, abduction positions. Common presentation will be hypotropia with drooping of upper eyelid. This was thought to be due to paresis of the two eye elevators, the superior rectus and inferior oblique (two elevators of the eye and hence, termed as double elevator palsy) [1]. MED can be caused by inferior rectus restriction and supranuclear etiology [2]. Its incidence is about $0.5 \%$ among strabismic patients [3]. In a case of MED when the person fixes with the normal eye, the affected eye shows hypotropia and pseudoptosis. When the affected eye is fixed ptosis in the affected eye disappears, but the normal eye shows hypertropia.

Monocular elevation deficiency is an uncommon eye disease. The literature search revealed very few reports on this eye condition from India [4]-[6]. The available studies reported different surgical plans with variable outcomes. However, the surgical management of congenital MED with exotropia as performed in this case is not available in the literature. We report a young lady with congenital monocular elevation deficiency with exotropia with good cosmetic results after sequential surgical procedures.

\section{CASE REPORT}

A 20-year-old lady presented to pediatric ophthalmology and squint clinic of a tertiary care teaching hospital with complaints of drooping of left upper eyelid since childhood (Fig. 1A). On examination patient was fixing with right eye, minimal chin elevation was noted. Ptosis was seen in left eye which disappeared on fixating with left eye (pseudoptosis) (Fig. 1B). In primary gaze left eye was 40-45 PD hypotropic and 35-40 PD exotropic (XT); in upgaze 45-50 PD hypo and 40-45 PD XT, and in down gaze 30 PD hypo and 25-30 XT. Patient can fix with left eye resulting in right eye hypertropia of 50-60 PD. Restriction of left eye elevation in adduction, primary and abduction positions. (Fig. 1C and 1D.).

Vision in Right eye was 6/6 and in left eye 6/9 for distance; near vision was normal. Intra ocular pressure was $15 \mathrm{~mm} \mathrm{Hg}$ in right eye and $16 \mathrm{~mm} \mathrm{Hg}$ in left eye with applanation tonometry. Bell's phenomenon was good and corneal sensation was normal in both eyes. Cycloplegic refraction did not show any refractive error in both eyes. The forced duction test (FDT) was performed for restriction of the inferior rectus, but the result was negative. Anterior and posterior segment examination did not reveal any abnormality in both eyes. CT scan of orbits and brain imaging and blood tests results were within normal limits. 

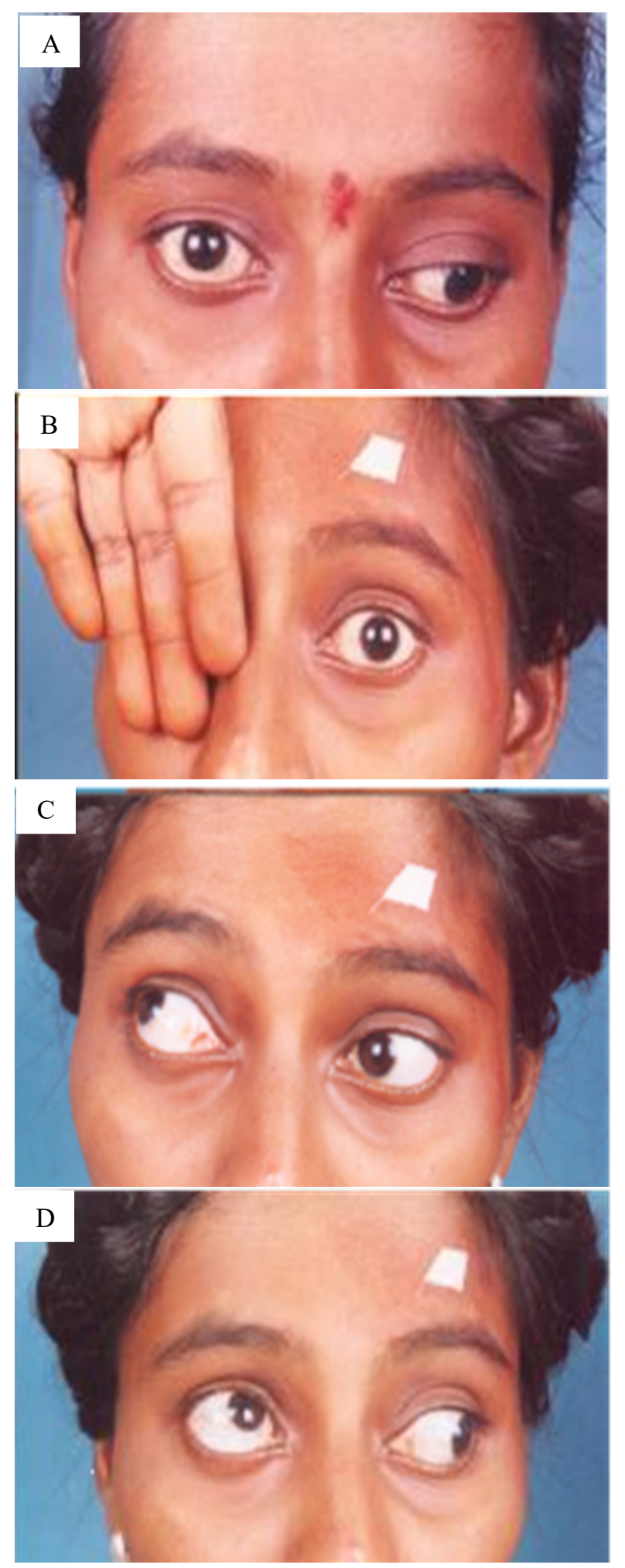

Fig. 1. Preoperative photos:

(A) exotropia, hypotropia and ptosis of left eye,

(B) left eye is fixing and ptosis disappears - pseudoptosis,

(C) dextro elevation limitation of left eye - Inferior oblique,

(D) levo elivation limitation of left eye - superior rect.

After taking a detailed pediatric history, neurological checkup was done to rule out acquired MED. Based on these findings, the diagnosis of congenital monocular elevation deficiency with exotropia in the left eye was made.

Patient was explained about the left eye condition and surgical treatment was advised. Based on our bad experience of simultaneous surgery (in one sitting) for hypo and exotropia in the previous cases with poor cosmetic results, we planned staged surgery separately. First sitting exotropia was corrected by doing lateral rectus recession $9 \mathrm{~mm}$, and medial rectus resection $5 \mathrm{~mm}$ under assisted local anesthesia (anaesthetist monitoring the vital signs of the patient during operation) for left eye. She was discharged after a day. Postoperatively, antibiotic, and steroid combination eye drops 4 time a day along with oral serrapeptase $10 \mathrm{mg} 3$ times a day for one week. After three days following the operatiomn, the patient was discharged and followed once in 2 weeks; the frequency of eye drops was tapered weekly. After the surgery, the patient was orthotropic horizontally, with hypotropia similar to that of presentation.

Four weeks after first surgery, second surgery was performed to correct hypotropia in the left eye by doing $5 \mathrm{~mm}$ superior rectus resection and $5 \mathrm{~mm}$ inferior rectus recession under assisted local anaesthesia. Post operatively patient was fixing with left eye; there was no ptosis in the left eye, but right eye was hypertropic in primary position (Fig. 2).

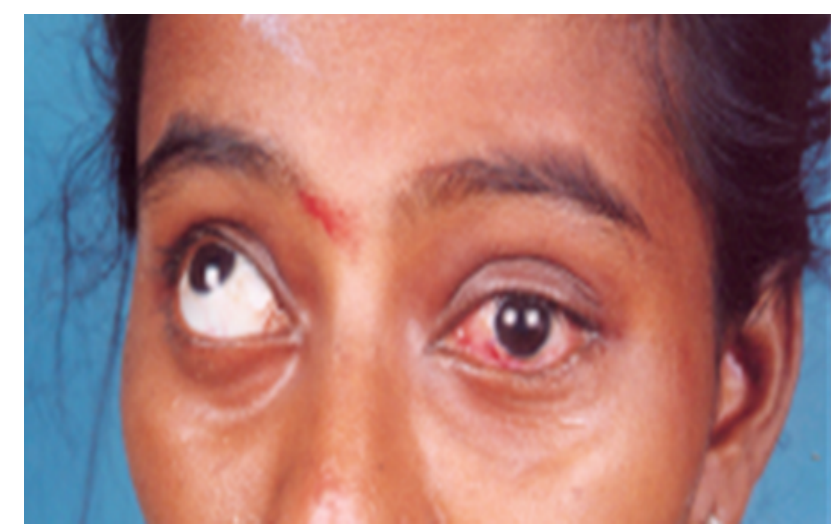

Fig. 2. Postoperative photo after second surgery showing left eye fixing no ptosis and eye is straight. However, right eye is hypertropic.

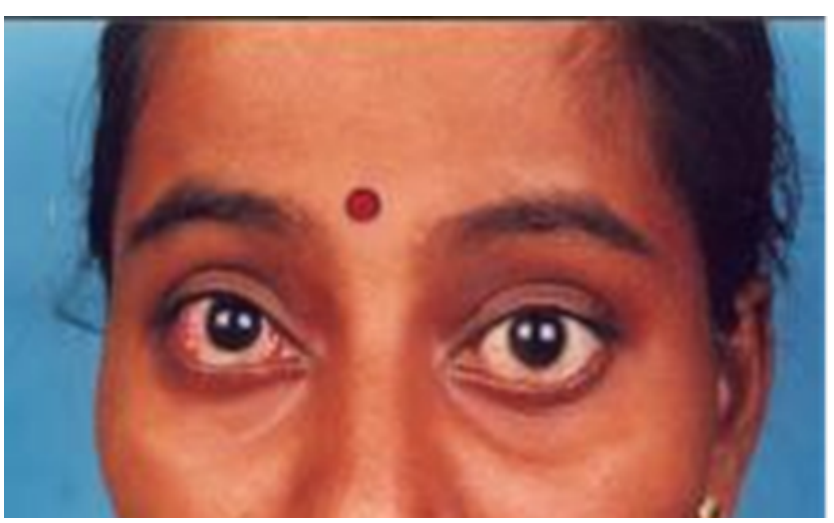

Fig. 3. Postoperative after third surgery showing both eyes are looking straight in primary position (orthotropic).

planned staged surgery separately. First sitting exotropia was corrected by doing lateral rectus recession $9 \mathrm{~mm}$, and medial rectus resection $5 \mathrm{~mm}$ under assisted local anesthesia (anaesthetist monitoring the vital signs of the patient during operation) for left eye. She was discharged after a day. Postoperatively, antibiotic and steroid combination eye drops 4 time a day along with oral serrapeptase $10 \mathrm{mg} 3$ times a day for one week. After three days following the operation, the patient was discharged and followed once in 2 weeks; the frequency of eye drops was tapered weekly. After the surgery, the patient was orthotropic horizontally, with hypotropia similar to that of presentation. 
Four weeks after first surgery, second surgery was performed to correct hypotropia in the left eye by doing $5 \mathrm{~mm}$ superior rectus resection and $5 \mathrm{~mm}$ inferior rectus recession under assisted local anaesthesia. Post operatively patient was fixing with left eye; there was no ptosis in the left eye, but right eye was hypertropic in primary position (Fig. 2).

The patient was counselled and convinced that up looking right eye will be straight after the surgery in that eye. Four weeks later, right eye hypertropia was corrected by doing 5 $\mathrm{mm}$ superior rectus recession and $5 \mathrm{~mm}$ inferior rectus resection under assisted local anaesthesia. Post operatively patient was orthotropic and both eyes were looking straight (Fig. 3). After 3 surgeries exodeviation was 8-10 PD and vertical deviation was 6-8 PD which is acceptable cosmetically.

The patient was followed up once in 3 months for one year after $3^{\text {rd }}$ surgery. At the last follow up, both eyes were orthotropic. The preoperative vision was maintained in both eyes. She was very happy and highly satisfied with cosmetic result. All the surgeries were performed by a single surgeon (VCR).

\section{DisCUSSION}

The defective elevation in MED can be explained by the presence of a superior rectus palsy alone [7]. In the presence of a normal superior rectus, inferior rectus (IR) restriction can also cause MED. Secondary contracture of the IR due to a primary SR palsy can also lead to MED [8]. Thickened IR in a few patients of MED with normal third nerve on MRI examination supported this [9]. Unilateral supranuclear lesion in the pretectal area near or inside the third cranial nerve nucleus could be a cause in some case [10].

The goal of surgery is to improve the position of the affected eye in primary gaze and to increase binocular field of vision. Available surgical treatment options for Monocular elevation deficiency are Knapp procedure, modified Knapp, and augmented Knapp, inferior rectus recession and recession and resection of vertical muscles [11]-[13], [1]. In this case Knapp procedure was avoided so that horizontal muscle surgery can be done for correction of exotropia. Hypotropia and elevation deficiency was corrected by vertical muscles surgery.

Association of horizontal deviation is quite common in congenital MED. Simultaneous surgery for both exo and hypotropias were not giving cosmetically acceptable results in our experience. Therefore, we planned for separate surgical sittings for exo and hypotropias. The rationale is to utilize horizontal muscles fully for exotropia correction. Management of MED depends upon selection of the correct surgical technique based on employing the results of forced duction test, for a satisfactory outcome [4]. Even though Nagpal et al. [5] and Callahan [14] claimed good results, we were not happy with simultaneous surgery.

In Knapp technique, the transposed muscle is stretched which makes resection difficult and doing recession will negate the benefit of surgery. For management of MED cases with associated horizontal deviation partial tendon Knapp (Modified Knapp) procedure is described [15], in which the superior half horizontal muscles are shifted to the superior rectus muscle insertion, allowing the correction of horizontal deviation with the inferior half. Ficker et al. [16] reported simultaneous horizontal rectus recession or resection with a Knapp procedure in cases of congenital MED.

Cooper et al. [13] did Knapp procedure with simultaneous resection and recession of horizontal muscles. But horizontal corrections were not satisfactory. Kamalesh et al. [6] concluded that vertical muscles resection and recession is a good alternative for MED with predictable amount of correction especially in patients with higher preoperative deviation. It spares horizontal muscles for correction of any associated horizontal deviation.

In our patient, the first surgery corrected the exoptropia and the second surgery corrected the hypotropia in the left eye. However, following this, right eye showed hypertropia in the primary position. This could probably be due to residual hypo of left eye. When the left eye is fixing right eye elevators act more and results in hypertropia of right eye (Hering's law) and large pre op hypotropia. Patient was assured that after third surgery in the right eye, both eyes will be straight looking in primary position. The patient was very happy and highly satisfied with cosmetic appearance of the eyes.

\section{CONCLUSION}

Sequential surgical treatment was planned and performed in this patient in view of bad experience of simultaneous correction of exotropia and hypotropia in the single sitting, with unsatisfactory cosmetic results in our previous patients. Even though the patient has undergone surgery three times, she was very happy with good cosmetic results. Knapp procedure was avoided in this case to spare horizontal recti totally for correction of exotropia which gave expected correction. Simultaneous surgeries for horizontal and vertical deviation are not giving good results cosmetically. Correction of horizontal and vertical deviations separately results in very good correction with no chance of anterior segment ischemia.

\section{REFERENCES}

[1] L. Rosenbaum, A. P. Santiago, "Principles and Surgical Techniques." W.B. Saunders Company; 1999. Clinical strabismus management; pp. 272-9, 1999.

[2] K. Wright, P. H. "Paediatric ophthalmology and strabismus," Spigel, Springer. 2nd ed., pp. 257-8, 2003.

[3] G. Kocak, I. Koçak, A. Argin, S. Duman, "Correction of ptosis or pseudoptosis in congenital double elevator palsy by either extraocular muscle or lid surgery," Ann Ophthalmol, 35: 57-61, 2003.

[4] R. Bandyopadhyay, S. Shetty, P. Vijayalakshmi, "Surgical outcome in monocular elevation deficit: A retrospective interventional study," Ind J Ophthalmol, 56:127-33, 2008.

[5] R. C. Nagpal, A. Raj, A. Maitreya, "Congenital double elevator palsy with sensory exotropia: A unique surgical management," J Ophthalmic Vis Res, 12: 222-4, 2017.

[6] G. A. Kamlesh, S. Dhiman, P. Thacker, B. Karothiya, Y. Goel, A. Rastogi, R. Chaudhary, "To assess the efficacy of vertical muscle surgery for management of hypotropia in monocular elevation deficiency type II," Int Ophthalmol, 37(4): 1009-16, 2017.

[7] G. K. Von Noorden, "Binocular vision and ocular motility," 6th ed. St Louis: Mosby; 2002.

[8] W. E. Scott, O. B. Jackson, "Double elevator palsy: the significance of inferior rectus restriction.” Am Orthop J., 27:5-10, 1977.

[9] J. H. Kim, J. M. Hwang, "Congenital Monocular Elevation Deficiency Ophthalmology," 116:580-4, 2006.

[10] R. S. Jampel, P. Fells, "Monocular elevation paresis caused by a central nervous system lesion." Arch Ophthalmol, 80(1):45-57, 1968. 
[11] P. Knapp, "The surgical treatment of double elevator paralysis," Trans Am Ophthalmol Soc. 67:304-23, 1969.

[12] J. P. Burke, J. B. Ruben, W. E. Scott, "Vertical transposition of the horizontal recti for the treatment of double elevator palsy: Effectiveness and long-term stability." $\mathrm{Br} J$ Ophthalmol. 76:734-7, 1992.

[13] E. L. Cooper, J. Greenspan, "Operation for double elevator palsy," J Pedtr Ophthalmol, 8:8-14, 1971.

[14] M. A. Callahan, "Surgically mismanaged ptosis associated with double elevator palsy," Arch Ophthalmol, 99:108-12, 1981.

[15] G. A. Kamlesh, S. Dadeya, "Surgical management of unilateral elevator deficiency associated with horizontal deviation using a modified Knapp's procedure," Ophthalmic Surg Lasers Imaging, 34:230-5, 2003.

[16] L. A. Ficker, J. R. Collin, J. P. Lee, "Management of ipsilateral ptosis with hypotropia," Br J Ophthalmol, 70:732-6, 1986. 